\title{
Rheological Behavior Models of Polymers
}

\author{
Rachid Hsissou 1,* (D), Miloudi Hilali ${ }^{2}$, Omar Dagdag ${ }^{1}$, Fatima Adder ${ }^{1}$, Abderrahim Elbachiri ${ }^{3}$, Mohamed \\ Rafik ${ }^{1}$ \\ Faculty of Sciences, University Ibn Tofail, BP 242, 14000, Kenitra, Morocco \\ Faculty of Sciences, University Mohamed V, BP 1014, Rabat, Morocco \\ Royal Naval School, University Department - Boulevard Sour- Jdid, Casablanca, Morocco \\ Correspondence: r.hsissou@gmail.com;
}

Scopus Author ID 57193233249

Received: 12.02.2021; Revised: 8.04.2021; Accepted: 14.04.2021; Published: 26.04.2021

\begin{abstract}
We studied and investigated the various viscosimetric and rheological polymers' behaviors during this comprehensive review. The viscosities relate to the investigation of the flux, the deformation, and the polymers' elasticity; we have employed the viscosity since this plays a primordial role in the phenomena flux and implementation of the polymer. The rheology behaviors were investigated for the determination of the physical properties of polymers. The rheological properties are mostly employed for improving polymers implementation. Further, three rheological behaviors models such as Newtonian, pseudo-plastic (Power Law, Law of Tile and Cross Law) and heat-dependent pseudo-plastic (Williams-Landel-Ferry Law (WLF), Law of Tile-Yasuda and Arrhenius law) were studied.
\end{abstract}

Keywords: comprehensive review; rheological behaviors; polymers; Newtonian and pseudo-plastic models.

(C) 2021 by the authors. This article is an open-access article distributed under the terms and conditions of the Creative Commons Attribution (CC BY) license (https://creativecommons.org/licenses/by/4.0/).

\section{Introduction}

Polymer composite materials (a mixture of two or more polymers) are an excellent alternative to the synthesis of polymers with improved properties and may exhibit combinations of properties in general superior to those of pure components [1-3]. Then, polymer composites can be elaborated by conventional machines used in industry, such as extruders, internal mixers, and injection molding machines [4-8]. Composite polymers can be used as low shear rate Newtonian fluids, generally in the vicinity of $1 \mathrm{~S}^{-1}$, and as high shear rate non-Newtonian fluids. In the injection molding process, the shear rate generally reaches $106 \mathrm{~S}^{-1}$, which is well beyond the traditional rheometer limits [9-14]. Many viscometers have been developed according to the fluid's nature to be studied [15-19]. Devices employed for extruders are prepared with thin matrices that allow elasticities and viscosities to be determined but at a low shear rate. The purpose of the original rheometer on injection or extrusion polymer processing machines is to allow the determination of various rheological properties such as viscosity, elasticity, and/or compressibility, under actual processing conditions, without disturbing the processing cycle, in a minimum of time and with a high degree of accuracy [2025]. It can be used both as a device for measuring and determining the rheological behavior laws of plastics or as a machine control and regulation device, in which case it can be controlled directly by the machine's microprocessor [26-31]. Rheology is the technology that studies the distortion of bodies under the effect of speed stresses. Also, it studies the relationship between stress and strain as a function of time in the material [32-37]. Generally speaking, rheology 
assumes that material is continuous (no voids in the material), each point of the body moves continuously, two points of the body that are infinitely adjacent before the deformation are still infinitely adjacent after the deformation and physical properties of the body vary continuously from one point to another, respectively. Rheology can be classified into two types [38-43]: Experimental rheology determines the behavioral relationship between stress and strain rate experimentally; Theoretical rheology provides a limited number of mathematical models of the behavior independently of the microscopic structure;

Gaseous, liquid, or solid bodies are divided into two classes as Newtonian fluids (these are all gases and a large number of liquids; their rheological equation is simple these bodies have only one rheological characteristic: viscosity) and bodies with complicated rheological equations: these are non-Newtonian liquids and solids [44-48].

Therefore, in the case of polymers rheology, only studies displacements that are large relative to the size of the macromolecules. Intramolecular movements and chain entanglement are movements that rheology by nature cannot describe. Then, these local movements are the basis for explaining the rheological behavior of molten polymers [49-53].

Viscosity is a very important parameter in the study of polymer flow. The latter, which is about $10^{6}$ to $10^{8}$ times that of water, is a function of certain parameters such as weight of the polymer, temperature, pressure and shear rate, respectively.

\section{Rheological Behavior in Dynamic Regime (Low Deformations)}

defined The strain $\gamma(\mathrm{t})$ and the stress $\sigma(\mathrm{t})$ were defined according to the following relations (Equations 1 and 2) [28, 29]:

$$
\begin{aligned}
& \gamma(t)=\gamma_{0} e^{i \varpi t} \\
& \tau(t)=\tau_{0} e^{i(\varpi t+\delta)}
\end{aligned}
$$

Where $\gamma_{0}$ and $\tau_{0}$ denote the maximum amplitudes of the strain and stress, respectively, $\mathrm{t}$ is time. Further, the complex modulus $\mathrm{G}^{*}$ was calculated from strain and stress according to Equation $3[28,29]$. Also, the complex modulus $G^{*}$ was composed of two parts, such as a real part $\left(\mathrm{G}^{\prime}\right)$ and an imaginary part (G') according to the following Equation 4 . Then, The loss factor and the complex viscosity $\eta^{*}$ were measured according to the following Equations 5 and $6[28,29]$ :

$$
\begin{aligned}
& \mathrm{G}^{*}=\frac{\tau(\mathrm{t})}{\gamma(\mathrm{t})}=\frac{\tau}{\gamma_{0}} \mathrm{e}^{\mathrm{i} \delta} \\
& \mathrm{G}^{*}=\mathrm{G}^{\prime}+\mathrm{iG} \mathrm{G}^{\prime \prime} \\
& \tan \delta=\frac{\mathrm{G}^{\prime \prime}}{\mathrm{G}^{\prime}} \\
& \eta^{*}=\eta^{\prime}+\mathrm{i}^{\prime \prime}
\end{aligned}
$$

2.1. Rheological behavior in the statistical regime.

In statistical regime, the viscosity $\eta$ was determined from shear stress $\tau$ and speed deformation $\gamma \cdot$ (Equation 7) [28, 29].

$$
\eta=\frac{\tau}{\gamma^{\bullet}}
$$


The viscosity don't depend to the speed of deformation, indicating for a Newtonian fluid, the stress is studied according to the deformation's speed. We obtained a line whose value of the slope is the viscosity, noted $\eta_{0}$ (Figure 1-a). When the viscosity evolves according to the speed of deformation, the fluid's behavior is called pseudo-plastic (Figure 1-b). In these two cases, these fluids deform immediately shear stress is applied. If the material does not deform (or little) below a certain, this is called threshold stress. The refore, the threshold constraint can be defined by the following relation (Equation 8) [28, 29].

$$
\tau_{\mathrm{y}}=\lim \sigma\left(\gamma^{\bullet}\right)
$$

Viscoelastic behaviors present threshold stress. At the high stress compared to the threshold stress, the viscosity does not depend on the viscosity of strain (Figure 1-c) [28, 29].

\subsection{Rheological behaviors.}

Thermosetting polymers are not Newtonian and their apparent viscosity decreasing according to the shear rate. This behavior is the pseudo-plasticity type at lower temperatures, the viscosity of polymer increases (the polymer is viscous). The flow speed of the polymer thermosetting between two edges changes, this variation was owing to the viscous polymers. Viscosity variation of polymers as a function of the shear rate and temperature are shown in Figure 2 [31].

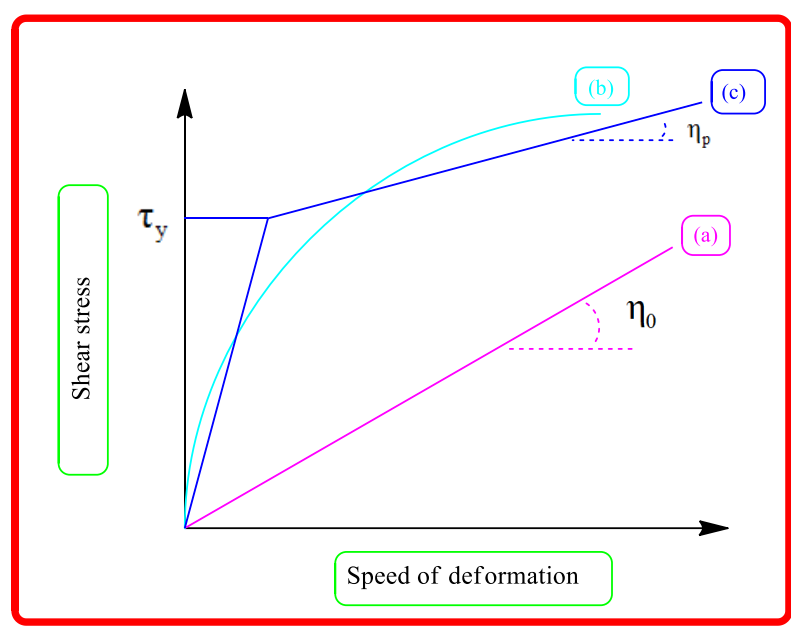

Figure 1. Varying rheological models: (a) Newtonian, (b) pseudo-plastic and (c) viscoelastic.

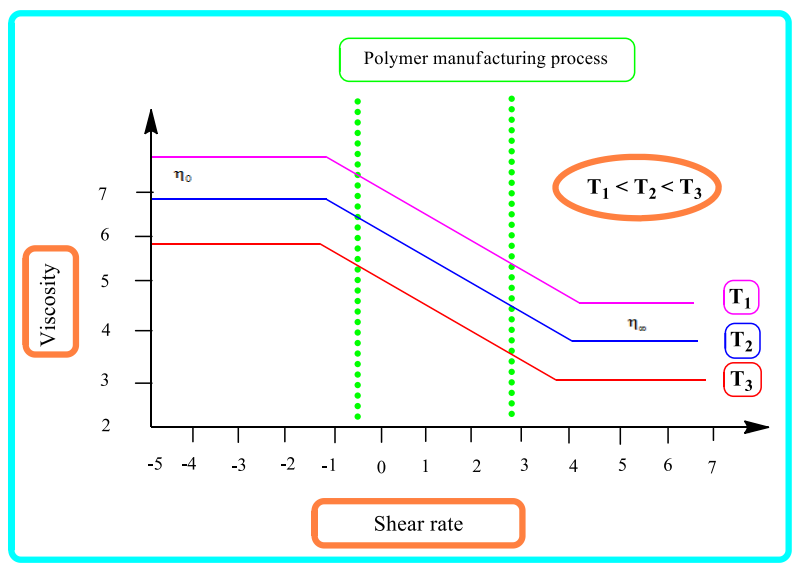

Figure 2. Viscosity as a function of the shear rate at different temperatures. 


\subsection{Varying viscosities models.}

Viscosities models most employed are Newtonian model, pseudo-plastic model and heat-dependent pseudo-plastic model, respectively.

\subsubsection{Newtonian model.}

The relation between stress and sheer speed presents the viscosity. Stress speed $u$ is proportional to this speed $\mathrm{F}=\mathrm{Ku}$. The components of the velocity vector are shown in the following equation $9[28,29,31]$ :

$$
\vec{u} \mid \begin{aligned}
& u=\dot{\gamma} \cdot y \\
& v=0 \\
& w=0
\end{aligned}
$$

This force related to the surface on which it is exerted the shear stress $\tau=\mathrm{F} / \mathrm{S}$ proportional to the sheer speed (Equation 10):

$$
\tau=\eta \cdot \gamma^{\bullet}
$$

The proportionality coefficient between $\tau$ and $\gamma \bullet$ was defined as a dynamic viscosity $\eta$ (Equation 11).

$$
\eta=\frac{\tau}{\gamma^{\bullet}}
$$

The shear stress as a function of the speed gradient is shown in Figure 3-a. However, The viscosity versus speed gradient shown a straight line parallel to the $\mathrm{X}$-axis [31].

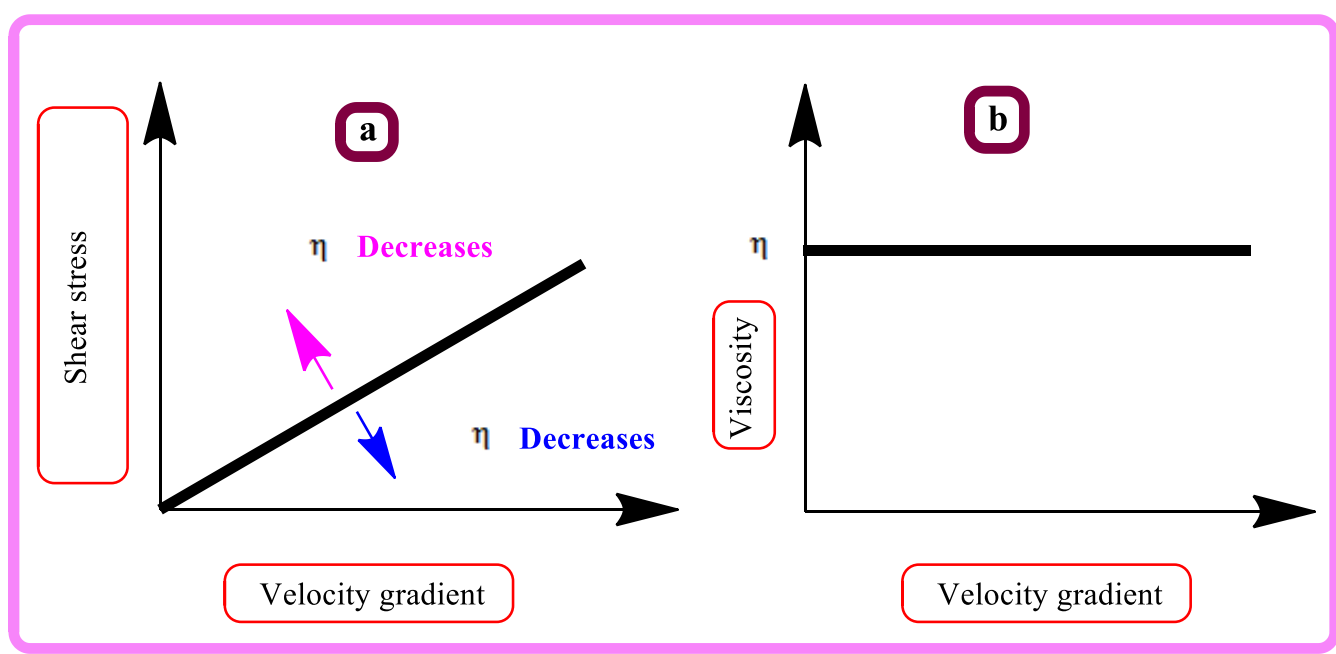

Figure 3. Viscosity of a Newtonian model.

\subsubsection{Pseudo-plastic model.}

Most polymers don't present the Newtonian models, this indicates that the viscosities are is not independent of the shear rate however decrease according to the shear rate. The pseudo-plastic model of polymer signified that the viscosity decreases according to the shear rate. The rheological models proposed are a power law, law of tile, cross law, heat-dependent 
pseudo-plastic, Williams-Landel-Ferry law, the law of Tile-Yasuda and Arrhenius law, respectively.

\subsubsection{Power law.}

The first behavior model for a non-carbonated fluid was developed by Ostwald-De Waele (Ostwald, 1923 and De Waele, 1923). It is written according to Equation 12 [54].

$$
\eta=K|\gamma| \bullet \mid m-1
$$

Where $\mathrm{K}$ and $\mathrm{m}$ denote the consistency material and index pseudo-plasticity, respectively.

We observed that this law gives a good account of polymers' behavior with a high shear rate. It offers the advantage of authorizing analytical calculations in simple geometries. On the other hand, it has the disadvantage of not having a Newtonian plateau and even of leading to an infinite viscosity at zero shear rates [54].

\subsubsection{Law of Tile.}

The Power Law model applies over a limited range of the viscosity curve. In reality, at low shear rates, the polymers have a Newtonian behavior, i.e., the viscosity is independent of the shear rate. Carreau has developed a model that completely represents the viscosity curve and supports this plateau; its model is written according to Equation 13 [55].

$$
\eta=\eta_{0}\left[1+\left(\lambda_{\gamma}\right)^{2}\right]^{(m-1) / 2}
$$

$\eta 0, \lambda$, and $\mathrm{m}$ are the zero shear viscosity, the time constant, and the index of the law of power, respectively.

Hieber and Chiang (1989) proposed a complete review of its various laws and their applications to the case of the main polymers.

\subsubsection{Cross Law.}

The cross model is a variant of the square model; it is written according to Equation 14.

$$
\eta-\eta_{\infty}=\frac{\left(\eta_{0}-\eta_{\infty}\right)}{1+\left(\lambda_{\gamma}\right)^{m}}
$$

With $\lambda, \eta_{0}$ and $\eta_{\infty}$ are a characteristic time, the viscosity of the Newtonian plateau at the low shear rate and second Newtonian plateau at a very high shear rate, respectively. The change in viscosity according to the shear rate depends on the number of parameters to be adjusted.

\subsubsection{Heat-dependent pseudo-plastic.}

The heat-dependent pseudo-plastic considers the variation in viscosity according to the shear rate and temperature. An elevate in temperature suggesting a decrease in viscosity due to the polymer chains' increased mobility. In order to investigate the temperature effect on 
viscosity, it is interesting to present the plot of viscosity according to shear stress for varying values of temperature. It is possible to drag all viscosities plots along a line at a constant shear rate to obtain a single plot. We can use the slip factor (ат), which is according to the temperature; it has shown the difference between a viscosity plot at temperature $(T)$ and the viscosity plot at the reference temperature $\left(\mathrm{T}_{\mathrm{ref}}\right)$. at can be calculated from an Arrhenius law for semi-crystalline polymers or from the equation of Williams-Landel-Ferry (WLF) for polymers amorphous to a temperature between $\mathrm{Tg}$ and $\mathrm{Tg}+100{ }^{\circ} \mathrm{C}$ (Equation 15) $[54,55]$.

$$
a_{T}=\exp \left[\frac{E}{R}\left(\frac{1}{T}-\frac{1}{T_{\text {ref }}}\right)\right]
$$

ат, E, R, T, and $\mathrm{T}_{\text {ref }}$ are the slip factor, the activation energy, the molar constant of ideal gases, the temperature, and the reference temperature, respectively.

\subsubsection{Williams-Landel-Ferry law (WLF).}

The empirical Williams-Landel-Ferry relation (relation or WLF law), associated with the principle of time-temperature equivalence, makes it possible to account for variations in the limiting viscosity of amorphous (non-crystalline) polymers according to the temperature. The WLF law also expresses the variation with the temperature of the translation factor. Mathematical processing calculates aт for each of the components M'and M'of the measured complex modulus $\mathrm{M}^{*}$. A good correlation between the two translation factors gives the values of the coefficients $C_{1}$ and $C_{2}$ characteristic of the material. The WLF law is only verified in the approximate temperature range $\left[\mathrm{Tg}, \mathrm{Tg}+100^{\circ} \mathrm{C}\right]$ (Equation 16) [56].

$$
a_{T}=\frac{\eta_{0}(T)}{\eta_{0}\left(T_{\text {réf }}\right)}=\exp \left[\frac{-C_{1}\left(T-T_{0}\right)}{C_{2}\left(T-T_{0}\right)}\right]
$$

The coefficients (or constants) $\mathrm{C}_{1}$ and $\mathrm{C}_{2}$ (positive) depend on the polymer considered and on $\mathrm{T}_{0}$ as a reference temperature suitably chosen.

\subsubsection{Law of Tile-Yasuda.}

To obtain viscosity at other temperatures, we used the time-temperature superposition principle (Equation 17) [54, 55].

$$
\eta_{\text {Tréf }} \stackrel{\bullet}{(\gamma)}=\eta_{0}\left[1+\left(\lambda_{\gamma}\right)^{2}\right]^{(m-1) / 2}
$$

\subsubsection{Arrhenius law.}

The activation energy was introduced by the Swedish scientist Svante August Arrhenius in 1889. After having noted the empirical law that bears his name and describes the changes in viscosity with temperature. The activation energy was determined according to the following Equations 18 and 19. 


$$
\begin{aligned}
& \eta=\eta_{\text {Tref }} \exp \left[\frac{E}{R}\left(\frac{1}{T}-\frac{1}{T_{\text {ref }}}\right)\right] \\
& \eta=\eta_{0} \exp \left(\frac{E}{R T}\right)
\end{aligned}
$$

$\mathrm{T}, \mathrm{E}, \mathrm{R}$ and $\eta_{0}$ are the temperature, the activation energy, the constant of ideal gases, and the constant.

\section{Conclusions}

This comprehensive review concerning the theoretical approach to rheological behavior allowed us to understand the phenomena relate to viscosimetric properties according to three models such as Newtonian model, pseudo-plastic model and pseudo-plastic thermo-dependent model, respectively.

The advantages of which are the determination of different thermodynamic parameters such as the activation energy $\left(\mathrm{E}_{\mathrm{a}}\right)$, the variation of the activation standard enthalpy $\left(\Delta \mathrm{H}_{\mathrm{a}}\right)$, the variation of the activation standard entropy $\left(\Delta \mathrm{S}_{\mathrm{a}}\right)$, and the variation of the free activation standard energy $\left(\Delta \mathrm{G}_{\mathrm{a}}\right)$.

\section{Funding}

This research received no external funding.

\section{Acknowledgments}

Many thanks to Prof. Abderrahim El Bachiri, who collaborated with excellent remarks and questions to give value to this paper's success.

\section{Conflicts of Interest}

The authors declare no conflict of interest.

\section{References}

1. Wang, X.; Tang, F.; Qi, X.; Lin, Z. Mechanical, electrochemical, and durability behavior of graphene nanoplatelet loaded epoxy-resin composite coatings. Composites Part B: Engineering 2019, 176, https://doi.org/10.1016/j.compositesb.2019.107103.

2. Hsissou, R.; Berradi, M.; El Bouchti, M.; El Bachiri, A.; El Harfi, A. Synthesis characterization rheological and morphological study of a new epoxy resin pentaglycidyl ether pentaphenoxy of phosphorus and their composite (PGEPPP/MDA/PN). Polym. Bull. 2019, 76, 4859-4878, https://doi.org/10.1007/s00289-0182639-9.

3. Hsissou, R.; Bekhta, A.; Khudhair, M.; Berradi, M.; El-Aouni, N.; Elharfi, A. Review on epoxy polymers composites with improved properties. Journal of Chemical Technology and Metallurgy 2019, 54, 11281136.

4. Arroub, H.; Hsissou, R.; Elharfi, A. Investigation of modified chitosan as potential polyelectrolyte polymer and eco-friendly for the treatment of galvanization wastewater using novel hybrid process. Results in Chemistry 2020, 2, 100047, https://doi.org/10.1016/j.rechem.2020.100047.

5. Hsissou, R.; Dagdag, O.; Berradi, M.; El Bouchti, M.; Assouag, M.; Elharfi, A. Development rheological and anti-corrosion property of epoxy polymer and its composite. Heliyon 2019, 5, e02789, https://doi.org/10.1016/j.heliyon.2019.e02789.

6. Utekar, S.; V K, S.; More, N.; Rao, A. Comprehensive study of recycling of thermosetting polymer composites - Driving force, challenges and methods. Composites Part B: Engineering 2021, 207, https://doi.org/10.1016/j.compositesb.2020.108596.

7. Hsissou, R.; Dagdag, O.; Berradi, M.; El Bouchti, M.; Assouag, M.; El Bachiri, A.; Elharfi, A. Investigation of structure and rheological behavior of a new epoxy polymer pentaglycidyl ether pentabisphenol A of 
phosphorus and of its composite with natural phosphate. SN Applied Sciences 2019, 1:869, https://doi.org/10.1007/s42452-019-0911-8.

8. Hsissou, R.; Dagdag, O.; Abbout, S.; Benhiba, F.; Berradi, M.; El Bouchti, M.; Berisha, A.; Hajjaji, N.; Elharfi, A. Novel derivative epoxy resin TGETET as a corrosion inhibition of E24 carbon steel in $1.0 \mathrm{M} \mathrm{HCl}$ solution. Experimental and computational (DFT and MD simulations) methods. J. Mol. Liq. 2019, 284, 182192, https://doi.org/10.1016/j.molliq.2019.03.180.

9. Zhang, S.; Yang, P.; Bai, Y.; Zhou, T.; Zhu, R.; Gu, Y. Polybenzoxazines: Thermal Responsiveness of Hydrogen Bonds and Application as Latent Curing Agents for Thermosetting Resins. ACS Omega 2017, 2 , 1529-1534,https://doi.org/10.1021/acsomega.7b00075.

10. Arroub, H.; Hsissou, R.; El Harfi, A. Adsorption of $\mathrm{Zn} 2+$ and $\mathrm{Cu} 2+$ ions by activated carbon prepared from dates stones computational approach. Analytical and Bioanalytical Electrochemistry 2019, 11, 1398-1413.

11. Benhiba, F.; Serrar, H.; Hsissou, R.; Guenbour, A.; Bellaouchou, A.; Tabyaoui, M.; Boukhris, S.; Oudda, H.; Warad, I.; Zarrouk, A. Tetrahydropyrimido-Triazepine derivatives as anti-corrosion additives for acid corrosion: Chemical, electrochemical, surface and theoretical studies. Chem. Phys. Lett. 2020, 743, 137181, https://doi.org/10.1016/j.cplett.2020.137181.

12. Hsissou, R.; Berradi, M.; El Bouchti, M.; El Harfi, A. Morphological and rheological study of the epoxy polymer and their nanocomposite (NGTHTPTBAE/MDA/TSP) crosslinked by methylene dianiline and formulated by trisodium phosphate. Journal of the Turkish Chemical Society Section A: Chemistry, 2019, 6, 237-244, https://dx.doi.org/10.18596/jotcsa.477191.

13. Xu, C.; Miao, M.; Jiang, X.; Wang, X. Thermal conductive composites reinforced via advanced boron nitride nanomaterials. Composites Communications 2018, 10, 103-109,https://doi.org/10.1016/j.coco.2018.08.002.

14. Hsissou, R.; Abbout, S.; Berisha, A.; Berradi, M.; Assouag, M.; Hajjaji, N.; Elharfi, A. Experimental, DFT and molecular dynamics simulation on the inhibition performance of the DGDCBA epoxy polymer against the corrosion of the E24 carbon steel in $1.0 \mathrm{M} \mathrm{HCl}$ solution. J. Mol. Struct. 2019, 1182, 340-351, https://doi.org/10.1016/j.molstruc.2018.12.030.

15. Benhiba, F.; Hsissou, R.; Benzekri, Z.; Belghiti, M.E.; Lamhamdi, A.; Bellaouchou, A.; Guenbour, A.; Boukhris, S.; Oudda, H.; Warad, I.; Zarrouk, A. Nitro substituent effect on the electronic behavior and inhibitory performance of two quinoxaline derivatives in relation to the corrosion of mild steel in $1 \mathrm{M} \mathrm{HCl}$. J. Mol. Liq. 2020, 312, 113367, https://doi.org/10.1016/j.molliq.2020.113367.

16. Bekhta, A.; Hsissou, R.; Berradi, M.; El Bouchti, M.; Elharfi, A. Viscosimetric and rheological properties of epoxy resin TGEUBA and their composite (TGEUBA/MDA/TGEMDA+TSP). Results in Engineering 2019, 4, 100058, https://doi.org/10.1016/j.rineng.2019.100058.

17. Bekhta, A.; Hsissou, R.; Elharfi, A. Evaluation of Mechanical compressive strength of cementitious matrix with $12 \%$ of IER formulated by modified polymer (NEPS) at different percentages. Sci. Rep. 2020, 10:2461, https://doi.org/10.1038/s41598-020-59482-6.

18. El-Aouni, N.; Hsissou, R.; Azzaoui, J.E.; Bouchti, M.E.; Elharfi, A. Synthesis rheological and thermal studies of epoxy polymer and its composite. Chemical Data Collections 2020, 30, 100584, https://doi.org/10.1016/j.cdc.2020.100584.

19. Dagdag, O.; Hsissou, R.; Berisha, A.; Erramli, H.; Hamed, O.; Jodeh, S.; El Harfi, A. Polymeric-Based Epoxy Cured with a Polyaminoamide as an Anticorrosive Coating for Aluminum 2024-T3 Surface: Experimental Studies Supported by Computational Modeling. Journal of Bio- and Tribo-Corrosion 2019, 5:58, https://doi.org/10.1007/s40735-019-0251-7.

20. Hsissou, R.; Abbout, S.; Safi, Z.; Benhiba, F.; Wazzan, N.; Guo, L.; Nouneh, K.; Briche, S.; Erramli, H.; Ebn Touhami, M.; Assouag, M.; Elharfi, A. Synthesis and anticorrosive properties of epoxy polymer for CS in $[1 \mathrm{M}] \mathrm{HCl}$ solution: Electrochemical, AFM, DFT and MD simulations. Construction and Building Materials 2021,270, 121454, https://doi.org/10.1016/j.conbuildmat.2020.121454.

21. Yang, H.; Cai, F.; Luo, Y.; Ye, X.; Zhang, C.; Wu, S. The interphase and thermal conductivity of graphene oxide/butadiene-styrene-vinyl pyridine rubber composites: A combined molecular simulation and $\begin{array}{llllll}\text { experimental } & \text { study. } & \text { Composites } & \text { Sci. } & \text { Technol. } & \text { 2020, }\end{array}$ https://doi.org/10.1016/j.compscitech.2019.107971.

22. Hsissou, R.; Bekhta, A.; Dagdag, O.; El Bachiri, A.; Rafik, M.; Elharfi, A. Rheological properties of composite polymers and hybrid nanocomposites. Heliyon 2020, 6, e04187, https://doi.org/10.1016/j.heliyon.2020.e04187.

23. Sharma, N.; Sharma, S. Anticorrosive coating of polymer composites: A review. Materials Today: Proceedings 2020, in press,https://doi.org/10.1016/j.matpr.2020.10.726.

24. Dagdag, O.; Hsissou, R.; El Harfi, A.; Berisha, A.; Safi, Z.; Verma, C.; Ebenso, E.E.; Ebn Touhami, M.; El Gouri, M. Fabrication of polymer based epoxy resin as effective anticorrosive coating for steel: Computational modeling reinforced experimental studies. Surfaces and Interfaces 2020, 18, 100454, https://doi.org/10.1016/j.surfin.2020.100454.

25. Dagdag, O.; Hsissou, R.; El Harfi, A.; Safi, Z.; Berisha, A.; Verma, C.; Ebenso, E.E.; Quraishi, M.A.; Wazzan, N.; Jodeh, S.; El Gouri, M. Epoxy resins and their zinc composites as novel anticorrosive materials for copper in 3\% sodium chloride solution: Experimental and computational studies. J. Mol. Liq. 2020, 315, 113757, https://doi.org/10.1016/j.molliq.2020.113757. 
26. Dagdag, O.; Safi, Z.; Hsissou, R.; Erramli, H.; El Bouchti, M.; Wazzan, N.; Guo, L.; Verma, C.; Ebenso, E.E.; El Harfi, A. Epoxy pre-polymers as new and effective materials for corrosion inhibition of carbon steel in acidic medium: Computational and experimental studies. Sci. Rep. 2019, 9, 11715, https://doi.org/10.1038/s41598-019-48284-0.

27. El Harfaouia, N.; Khaaissa, Y.; Nouneh, K.; Belahmar, A.; Talbi, A.; El Mabrouk, K.; Hsissou, R.; Feddi, E.M.; Taleb, A.; El Mouakibi, A. One pot synthesis of silver nanoparticles on ITO surfaces: investigation of optical and electrochemical properties. Eur. Phys. J. Appl. Phys. 2020, 91, 30401, https://doi.org/10.1051/epjap/2020200130.

28. Hsissou, R.; Bekhta, A.; Elharfi, A. Viscosimetric and rheological studies of a new trifunctional epoxy prepolymer with noyan ethylene: Triglycidyl Ether of Ethylene of Bisphenol A (TGEEBA). J. Mater. Environ. Sci 2017, 8, 603-610.

29. Hsissou, R.; El Bouchti, M.; Elharfi, A. Elaboration and viscosimetric, viscoelastic and rheological studies of a new hexafunctional polyepoxide polymer: Hexaglycidyl Ethylene of Methylene Dianiline. J. Mater. Environ. Sci 2017, 8, 4349-4361

30. Mouna, E.A.; Selma, C.; Hsissou, R.; Samira, K.; Mohammed, A. Gravimetric and electrochemical investigation of the anticorrosion performance by polystyrene coating on E24 carbon steel in acid medium. Analytical and Bioanalytical Electrochemistry 2019, 11, 1735-1746.

31. Hsissou, R.; Elharfi, A. Rheological behavior of three polymers and their hybrid composites (TGEEBA/MDA/PN), (HGEMDA/MDA/PN) and (NGHPBAE/MDA/PN). Journal of King Saud University - Science 2020, 32, 235-244, https://doi.org/10.1016/j.jksus.2018.04.030.

32. Debbeche, H.; Toffano, M.; Kolodziej, E.; Fiaud, J.-C.; Aribi-Zouioueche, L. Insight into the stereoselectivity of PPL-catalyzed formation of polyesters from phenyl glycidyl ether and succinic anhydride. Eur. Polym. J. 2012, 48, 1323-1328, https://doi.org/10.1016/j.eurpolymj.2012.04.005.

33. Zhu, Q.; Li, E.; Liu, X.; Song, W.; Li, Y.; Wang, X.; Liu, C. Epoxy coating with in-situ synthesis of polypyrrole functionalized graphene oxide for enhanced anticorrosive performance. Prog. Org. Coat. 2020, 140, https://doi.org/10.1016/j.porgcoat.2019.105488.

34. Hsissou, R.; Benhiba, F.; Khudhair, M.; Berradi, M.; Mahsoune, A.; Oudda, H.; El Harfi, A.; Obot, I.B.; Zarrouk, A. Investigation and comparative study of the quantum molecular descriptors derived from the theoretical modeling and Monte Carlo simulation of two new macromolecular polyepoxide architectures TGEEBA and HGEMDA. Journal of King Saud University - Science 2020, 32, 667-676, https://doi.org/10.1016/j.jksus.2018.10.008

35. Hsissou, R.; Bekhta, A.; Elharfi, A. Synthesis and characterization of a new epoxy resin homologous of DGEBA: diglycidyl bis disulfide carbon ether of bisphenol A. Journal of Chemical Technology and Metallurgy 2018, 53, 414-421.

36. Su, Z.; Wang, H.; Tian, K.; Huang, W.; Guo, Y.; He, J.; Tian, X. Multifunctional anisotropic flexible cycloaliphatic epoxy resin nanocomposites reinforced by aligned graphite flake with non-covalent biomimetic functionalization. Composites Part A: Applied Science and Manufacturing 2018, 109, 472480,https://doi.org/10.1016/j.compositesa.2018.02.033.

37. Hssissou, R.; Benzidia, B.; Hajjaji, N.; Elharfi, A. Elaboration, Electrochemical Investigation and morphological Study of the Coating Behavior of a new Polymeric Polyepoxide Architecture: Crosslinked and Hybrid Decaglycidyl of Phosphorus Penta methylene Dianiline on E24 Carbon Steel in 3.5\% NaCl. Portugaliae Electrochimica Acta 2019, 37, 179-191, http://dx.doi.org/10.4152/pea.201903179.

38. Hsissou, R.; Benzidia, B.; Hajjaji, N.; Elharfi, A. Elaboration and electrochemical studies of the coating behavior of a new nanofunctional epoxy polymer on E24 steel in 3.5\% NaCl. Portugaliae Electrochimica Acta 2018, 36, 259-270, http://dx.doi.org/10.4152/pea.201804259.

39. Shirazi, Z.; Golikand, A.N.; Keshavarz, M.H. A new nanocomposite based on poly (o-anthranilic acid), graphene oxide and functionalized carbon nanotube as an efficient corrosion inhibitor for stainless steel in severe environmental corrosion. Composites Communications 2020, https://doi.org/10.1016/j.coco.2020.100467.

40. Hsissou, R.; Bekhta, A.; Elharfi, A.; Benzidia, B.; Hajjaji, N. Theoretical and electrochemical studies of the coating behavior of a new epoxy polymer: hexaglycidyl ethylene of methylene dianiline (HGEMDA) on E24 steel in $3.5 \%$ NaCl. Portugaliae Electrochimica Acta 2018, 36, 101-117, http://dx.doi.org/10.4152/pea.201802101.

41. Rbaa, M.; Benhiba, F.; Hssisou, R.; Lakhrissi, Y.; Lakhrissi, B.; Touhami, M.E.; Warad, I.; Zarrouk, A. Green synthesis of novel carbohydrate polymer chitosan oligosaccharide grafted on d-glucose derivative as bio-based corrosion inhibitor. J. Mol. Liq. 2021, 322, 114549, https://doi.org/10.1016/j.molliq.2020.114549.

42. Liu, X.; Tian, F.; Zhao, X.; Du, R.; Xu, S.; Wang, Y.-Z. Recycling waste epoxy resin as hydrophobic coating of melamine foam for high-efficiency oil absorption. Appl. Surf. Sci. 2020, 529, https://doi.org/10.1016/j.apsusc.2020.147151.

43. Ma, Y.; Fan, B.; Zhou, T.; Hao, H.; Yang, B.; Sun, H. Molecular assembly between weak Crosslinking cyclodextrin Polymer and trans-cinnamaldehyde for corrosion inhibition towards Mild steel in $3.5 \% \mathrm{NaCl}$ Solution: Experimental and Theoretical Studies. Polymers 2019, 11, https://doi.org/10.3390/polym11040635. 
44. Hsissou, R.; El Harfi, A. Application of Pentaglycidyl ether Penta-ethoxy Phosphorus Composites Polymers Formulated by Two Additives, Trisodium Phosphate (TSP) and Natural Phosphate (NP) and their Combination in the Behavior of the Coating on E24 Carbon Steel in NaCl 3.5\%. Anal. Bioanal. Electrochem. 2018, 10, 728-738.

45. Qu, L.; Sui, Y.; Zhang, C.; Dai, X.; Li, P.; Sun, G.; Xu, B.; Fang, D. Improved flame retardancy of epoxy resin composites modified with a low additive content of silica-microencapsulated phosphazene flame retardant. React. Funct. Polym. 2020, 148, https://doi.org/10.1016/j.reactfunctpolym.2020.104485.

46. Hsissou, R.; Seghiri, R.; Benzekri, Z.; Hilali, M.; Rafik, M.; Elharfi, A. Polymer composite materials: A $\begin{array}{lllll}\text { comprehensive } \quad \text { review. } & \text { Composite } & \text { Structures } & \text { 2021, }\end{array}$ https://doi.org/10.1016/j.compstruct.2021.113640.

47. Hsissou, R., Berradi, M., Grich, M., Bahaj, H., El Bouchti, M., Khudhair, M., Es-sahbany, H., Rafik, M., Elharfi, A. Synthesis and investigati on of penta glycidyl ether penta phenoxy phosphoric polymer and formulati on of nanocomposite (PGEPPP/MDA/TiO2). Journal of Chemical Technology and Metallurgy 2019, 54, 893-901.

48. Zhang, L.F.; Gao, R.; Hou, J.; Zhao, B.L.; Sun, M.; Hao, T.; Xie, Z.M.; Liu, R.; Wang, X.P.; Fang, Q.F.; Liu, C.S. Study on thermal stability and irradiation response of copper/iron nano-multilayer composite fabricated by cross accumulative roll bonding. J. Nucl. Mater. 2021, 543, https://doi.org/10.1016/j.jnucmat.2020.152548.

49. Hsissou, R.; Benhiba, F.; Abbout, S.; Dagdag, O.; Benkhaya, S.; Berisha, A.; Erramli, H.; Elharfi, A. Trifunctional epoxy polymer as corrosion inhibition material for carbon steel in $1.0 \mathrm{M} \mathrm{HCl}$ : MD simulations, DFT and complexation computations. Inorg. Chem. Commun. 2020, 115, 107858, https://doi.org/10.1016/j.inoche.2020.107858.

50. Hsissou, R.; Benzidia, B.; Rehioui, M.; Berradi, M.; Berisha, A.; Assouag, M.; Hajjaji, N.; Elharfi, A. Anticorrosive property of hexafunctional epoxy polymer HGTMDAE for E24 carbon steel corrosion in 1.0 $\mathrm{M} \mathrm{HCl}$ : gravimetric, electrochemical, surface morphology and molecular dynamic simulations. Polymer Bulletin. 2020, 77, 3577-3601, https://doi.org/10.1007/s00289-019-02934-5

51. Hsissou, R.; Benhiba, F.; Echihi, S.; Benkhaya, S.; Hilali, M.; Berisha, A.; Briche, S.; Zarrouk, A.; Nouneh, K.; Elharfi, A. New epoxy composite polymers as a potential anticorrosive coatings for carbon steel in $3.5 \%$ $\mathrm{NaCl}$ solution: Experimental and computational approaches. Chemical Data Collections 2021, 31, 100619, https://doi.org/10.1016/j.cdc.2020.100619.

52. Souto, L.F.C.; Soares, B.G. Polyaniline/carbon nanotube hybrids modified with ionic liquids as anticorrosive additive in epoxy coatings. Prog. Org. Coat. 2020, 143, https://doi.org/10.1016/j.porgcoat.2020.105598.

53. Hsissou, R.; Benhiba, F.; Zarrouk, A.; Oudda, H.; Elharfi, A. Electrochemical studies, Monte Carlo simulation and DFT of a new composite - pentaglycidyl ether pentaphenoxy of phosphorus - crosslinked and hybrid in its coating behavior on E24 carbon steel in 3.5\% NaCl. Port. Electrochimica Acta 2021, 39, 1-19, https://doi.org/10.4152/pea.202101001.

54. Shapovalov, V.M. On the Applicability of the Ostwald-De Waele Model in Solving Applied Problems. Journal of Engineering Physics and Thermophysics2017, 90, 1213-1218, https://doi.org/10.1007/s10891017-1676-9.

55. Hemphill, T.; Campos, W.; Pilehvari, AYield-power law model more accurately predicts mud rheology. Oil and Gas j.1993. 91.

56. WLF law Felstiner. Influences of Social Organization on Dispute Processing. Law \&Soc'y Rev. 63 (19741975) https://heinonline.org/HOL/LandingPage?handle=hein.journals/lwsocrw9\&div=10\&id=\&page=. 